\title{
Comparison of regional and local anesthesia for arteriovenous fistula creation in end-stage renal disease: a systematic review and meta-analysis
}

\author{
Chen Gao', Chunyan Weng ${ }^{2}$, Chenghai $\mathrm{He}^{3^{*}} \mathbb{B}$, Jingli $\mathrm{Xu}^{2}$ and Liqiang $\mathrm{Yu}^{1}$
}

\begin{abstract}
Background: Arteriovenous fistulae (AVF) are the hemodialysis access modality of choice for patients with endstage renal disease. However, they have a high early failure rate. Good vascular access is essential to manage longterm hemodialytic treatment, but some anesthesia techniques directly affect venous diameter as well as intra- and post-operative blood flow. The main purpose of this meta-analysis was to compare the results of regional and local anesthesia (RA and LA) for arteriovenous fistula creation in end-stage renal disease.

Methods: We conducted a systematic review and meta-analysis to synthesize evidence from 7 randomized controlled trials (565 patients) and 1 observational study (408 patients) with the aim of evaluating the safety and efficacy of RA versus LA in surgical construction of AVF.

Results: Pooled data showed that RA was associated with higher primary patency rates than LA (odds ratio [OR], 1.88; $95 \%$ confidence interval $\left.[\mathrm{Cl}]: 1.24-2.84 ; P=0.003 ; I^{2}=31 \%\right)$. Additionally, brachial artery diameter was significantly increased in the RA versus LA group (mean difference [MD], 0.83; 95\% Cl: 0.75-0.92; $P<0.001 ; I^{2}=97 \%$ ) and the need for intra- as well as post-operative pain killers was significantly less (RA, $P=0.0363 ; \mathrm{LA}, P=0.0318$ ). Moreover, operation duration was significantly reduced using RA versus LA (MD, $-29.63 ; 95 \% \mathrm{Cl}$ : $32.78--26.48$; $\left.P<0.001 ;\left.\right|^{2}=100 \%\right)$.
\end{abstract}

Conclusions: This meta-analysis suggests that RA is preferable to LA in patients with end-stage renal disease in guaranteeing AVF patency and increasing brachial artery diameter.

Keywords: Arteriovenous fistula, End-stage renal disease, Local anesthesia, Regional anesthesia, Meta-analysis, Systematic review

\section{Background}

The construction of arteriovenous fistulae (AVF) is an established form of therapy for patients with chronic renal failure. However, the primary failure rate for AVF creation under local anesthesia (LA) for hemodialysis is

\footnotetext{
* Correspondence: hikiddhechenghai@163.com

${ }^{3}$ Department of Internal Medicine, The Affiliated Hospital of Hangzhou Normal University, 126 Wenzhou Road, Zhejiang, Hangzhou, China Full list of author information is available at the end of the article
}

very high; approximately one third of AVF fail at an early stage [1]. General anesthesia (GA), regional anesthesia (RA), and local anesthetic infiltration are three acceptable anesthetic techniques used for the surgical construction of AVF; however, the choice of anesthetic technique may significantly affect early patency or long-term AVF outcomes.

General anesthesia is associated with increased cardiorespiratory complications in patients with end-stage

C C The Author(s). 2020 Open Access This article is licensed under a Creative Commons Attribution 4.0 International License, which permits use, sharing, adaptation, distribution and reproduction in any medium or format, as long as you give appropriate credit to the original author(s) and the source, provide a link to the Creative Commons licence, and indicate if changes were made. The images or other third party material in this article are included in the article's Creative Commons licence, unless indicated otherwise in a credit line to the material. If material is not included in the article's Creative Commons licence and your intended use is not permitted by statutory regulation or exceeds the permitted use, you will need to obtain permission directly from the copyright holder. To view a copy of this licence, visit http://creativecommons.org/licenses/by/4.0/ The Creative Commons Public Domain Dedication waiver (http://creativecommons.org/publicdomain/zero/1.0/) applies to the data made available in this article, unless otherwise stated in a credit line to the data. 
renal disease. Thus, in such patients, RA, such as a brachial plexus block (BPB), or LA are favored for AVF creation. However, whilst both local anesthetic infiltration and RA avoid the risks associated with GA, only RA may be used to produce an associated sympathetic nerve block, which increases venous diameter and arterial flow intraoperatively, as well as in the early postoperative period.

Compared with LA, BPB is thought to improve local hemodynamic parameters. However, the effects of both techniques on fistula patency and failure rates are highly controversial. Therefore, we conducted a systematic review and meta-analysis to collect evidence from published randomized controlled trials (RCTs) and observational studies to assess the safety and efficacy of LA and RA in the surgical creation of AVF.

\section{Methods}

\section{Electronic searches}

This systematic review and meta-analysis followed the Preferred Reporting Items for Systematic Reviews and Meta-Analyses (PRISMA) statement recommendations. We searched the literature using PubMed, EMBASE, and Cochrane library databases, and included studies published from August 1951 to September 2017. The Medical Subject Headings (MESH) search query used were as follows: arteriovenous fistula OR (arteriovenous AND fistula) AND (anesthesia OR local anesthesia OR brachial plexus anesthesia OR regional anesthesia OR anesthesia OR regional anesthesia OR brachial plexus block OR brachial plexus anesthesia OR brachial plexus blockade OR local anesthesia OR conduction anesthesia OR infiltration anesthesia). We also reviewed the reference lists of eligible studies and reviews to identify any additional relevant studies. Disagreement over relevance was resolved by consensus.

\section{Study selection}

Study titles and abstracts were screened for eligibility by two independent reviewers. Eligible studies included open-label and double-blinded RCTs, as well as retrospective studies with adult open-label participants $(\geq 18$ years), that compared the efficacy of RA versus LA for AVF creation in end-stage renal disease. Studies meeting any of the following criteria were excluded: (a) animalbased studies; (b) studies not published in English; (c) abstracts, editorials, case reports, reviews, and case series.

The following data and outcomes were extracted and included in the study: (a) study characteristics (including: study design, sample size, follow-up duration, and publication year); (b) primary clinical outcomes (including: primary fistula patency rate, primary fistula failure rate, surgery duration, change in brachial artery diameter $(\mathrm{mm})$, change in brachial artery blood flow rate $(\mathrm{mL} /$ min), and post-surgery comorbidities).

\section{Data analyses and quality assessment}

We used Review Manager software (RevMan version 5.3) to analyze the extracted data. Odds ratios (ORs) were calculated with 95\% confidence intervals (CIs). Heterogeneity between ORs for the same outcomes across different studies were explored using the $\mathrm{I}^{2}$ inconsistency test, which describes the percentage of total variation across studies due to heterogeneity as opposed to chance. A value of $0 \%$ indicates no observed statistical heterogeneity, whilst larger values signify more substantial heterogeneity.

The studies were assessed using the Cochrane risk of bias tool (Fig. 2) and the Newcastle-Ottawa Scale (Table 1). Disagreements between the two independent investigators were resolved via discussion.

\section{Results}

Details of the auto-selection process are outlined in Fig. 1. Overall, 8 studies, including 7 RCTs [2-8] and 1 retrospective study, [9] with a total of 955 patients, met the inclusion criteria. The characteristics of all included studies are provided in Table 2 Details of the quality assessments are provided in Fig. 2 and Table 1.

\section{Clinical outcomes}

In total, 7 studies, including 852 patients, [2, 3, 5-9] evaluated primary patency rates in RA versus LA; RA was associated with higher primary patency rates than LA (OR, $1.88 ; 95 \%$ CI: $1.24-2.84 ; P=0.003 ; \mathrm{I}^{2}=31 \%$; Fig. 3). The combined data from 3 trials, [6-8] including 284 patients, demonstrated that RA was associated with significantly increased brachial artery diameters compared to LA (mean difference (MD), 0.83; 95\% CI: $0.75-$ $\left.0.92 ; P<0.001 ; \mathrm{I}^{2}=97 \%\right)$. The combined data from 2 trials, $[6,8]$ including 144 patients, revealed that LA was associated with significantly reduced branchial artery blood flow compared to RA (MD, 47.5; 95\% CI: 35.1859.12; $\left.P<0.001 ; I^{2}=83 \%\right)$. Two trials, $[4,6]$ including 229 patients, reported data regarding operative times, demonstrating significantly longer operative times in RA versus LA (MD, - $29.63 \mathrm{~min}, 95 \% \mathrm{CI}$ - 32.78 - -26.48; $\left.P<0.001 ; \mathrm{I}^{2}=100 \%\right)$. Details of the clinical outcomes are provided in Table 3.

\section{Complications}

The combined data from 3 trials, $[3,6,9]$ including 594 patients, demonstrated no difference between RA and LA in terms of vascular access infection (MD, 0.68; 95\% CI: $\left.0.23-2.02 ; P=0.49 ; \mathrm{I}^{2}=0 \%\right)$. Three trials, $[2,3,6]$ including 163 patients, revealed no significant difference between RA and LA with respect to the incidence of 
Table 1 Risk of bias assessment

\begin{tabular}{llll}
\hline Study & Selection & Comparability & Exposure \\
\hline Solomonson, et al. 1994 & $* *$ & $* *$ & $* * *$ \\
\hline
\end{tabular}

fistula thrombosis (OR, 0.21; 95\% CI: 0.03-1.27; $P=0.09$; $\left.\mathrm{I}^{2}=0 \%\right)$. Observations after BPBs in 1 trial, [3] including 60 patients, found no significant differences in the blocks until six-weeks post fistula creation (OR, 0.19; 95\% CI: 0.01-4.06; $P=0.29 ; \mathrm{I}^{2}=0 \%$ ). One trial, [4] including 103 patients, found a significant difference in pain intensity experienced between RA and LA $(P=0.0363$ versus $P=$ 0.0318 , respectively), and time to postoperative pain initiation was significantly longer following RA versus LA. Operative duration was significantly shorter $(P=0.0007)$ for RA $(67.5 \pm 8.9 \mathrm{~min})$ than LA $(134.7 \pm 14.8 \mathrm{~min})$.

\section{Discussion}

This meta-analysis included 955 patients from 8 studies ( 7 RCTs and 1 retrospective study). Combined data demonstrates that RA is associated with higher AVF primary patency rates and improved local blood flow compared with LA. Moreover, operation duration and the use of pain killers was significantly reduced with RA versus LA .
Axillary-approached BPB (RA) was preferable to LA. Arterial and venous dilation are crucial for AVF maturation [2] yet vascular surgery, such as local infiltration anesthesia, can easily lead to vessel spasm, impairing blood flow and potentially resulting in early fistula thrombosis. Comparatively, BPB can be performed using interscalene, supraclavicular, infraclavicular, and axillar approaches [4]. In a recent study, BPB was found to provide higher blood flow to the radial artery and AVF compared to infiltration anesthesia [3] given the sympatholytic effect, producing significant vasodilatation, decreased vascular resistance, [10] and increased local blood flow. This is consistent with other recent studies showing improvements in arterial blood flow and vasodilatation with RA. In a recent study by Nofal et al, [7] the overall mean AVF blood flow was $42.21 \mathrm{ml} / \mathrm{min}$ more in the BPB versus LA group. Similarly, a report by Malovrh [11] revealed a mean preoperative flow rate of $54.5 \mathrm{ml} / \mathrm{min}$ in $\mathrm{BPB}$ vessels with a successful outcome versus $24.1 \mathrm{ml} / \mathrm{min}$ in vessels that failed LA. In another

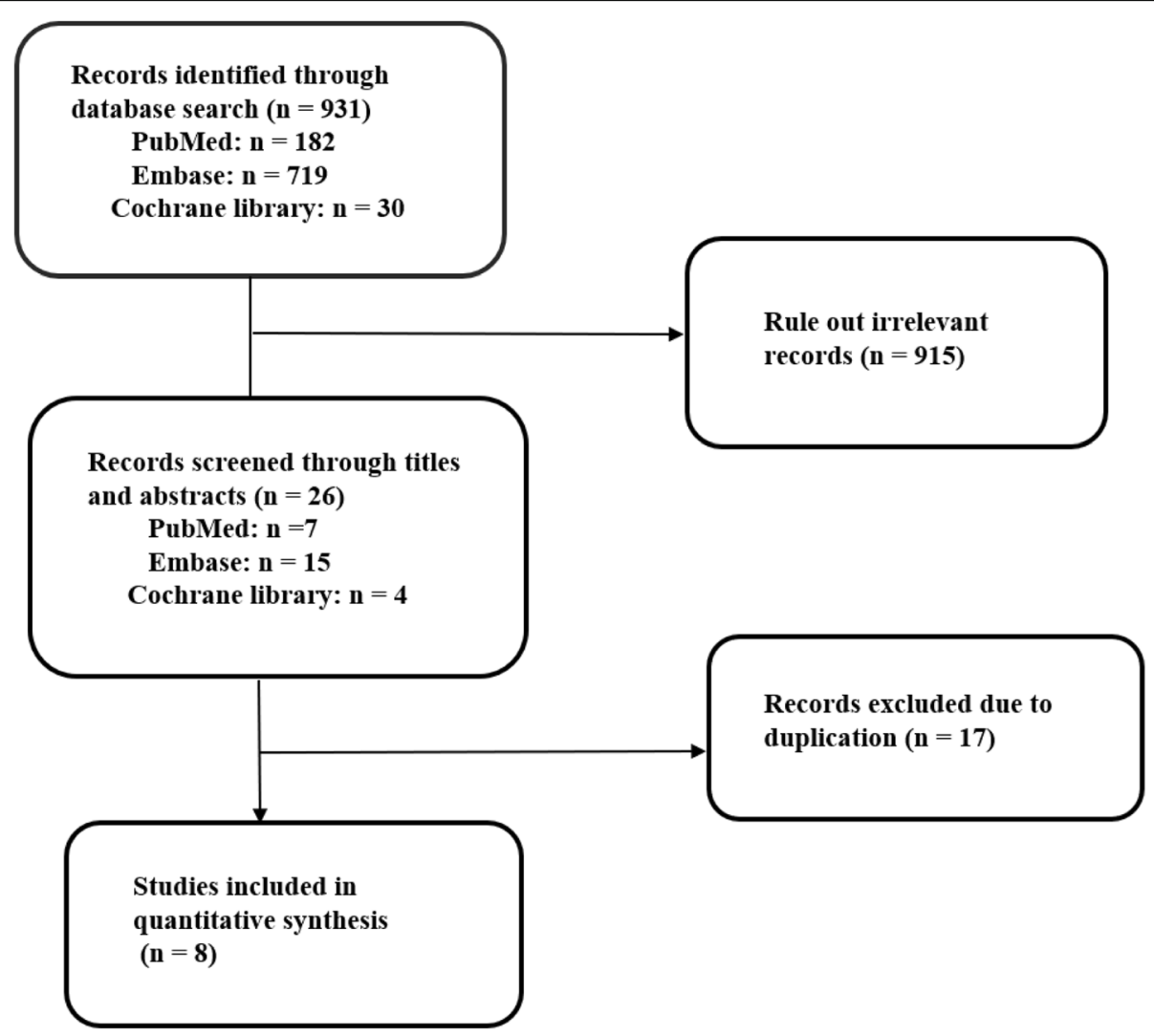

Fig. 1 Study selection flow diagram 
Table 2 Summary of included studies and baseline characteristics of their populations

\begin{tabular}{|c|c|c|c|c|c|c|c|}
\hline Study & $\begin{array}{l}\text { Design and } \\
\text { study arms }\end{array}$ & $\begin{array}{l}\text { Sample } \\
\text { size }(n)\end{array}$ & $\begin{array}{l}\text { Age } \\
(\mathrm{M} \pm \mathrm{SD} \text {, years })\end{array}$ & $\operatorname{Sex}(n)$ & Comorbidities $(n)$ & $\begin{array}{l}\text { Duration } \\
\text { of follow } \\
\text { up }\end{array}$ & Outcomes Examined \\
\hline $\begin{array}{l}\text { Mouquet, } \\
\text { et al. } 1989\end{array}$ & $\begin{array}{l}\text { RCT } \\
\text { (BPB vs. LA } \\
\text { or GA) }\end{array}$ & 18 & $52 \pm 16$ & $\begin{array}{l}\text { Male (23); } \\
\text { Female (13) }\end{array}$ & - & $\begin{array}{l}2 \mathrm{~h} ; 3 \text { days; } \\
10 \text { days }\end{array}$ & Brachial artery blood flow \\
\hline $\begin{array}{l}\text { Solomonson, } \\
\text { et al. } 1994\end{array}$ & $\begin{array}{l}\text { Retrospective } \\
\text { study } \\
\text { (BPB vs. LA } \\
\text { or GA) }\end{array}$ & 408 & $63 \pm 14$ & $\begin{array}{l}\text { Male (245); } \\
\text { Female } \\
(163)\end{array}$ & $\begin{array}{l}\text { Infection (16); Neuropathy } \\
\text { (9); Seizure (1); Cardiac } \\
\text { event (17) }\end{array}$ & - & $\begin{array}{l}\text { Fistula failure; Graft infection, } \\
\text { neuropathy in the extremity } \\
\text { receiving the fistula; Seizure; } \\
\text { Cardiac arrest; Ml; Death within } \\
7 \text { days }\end{array}$ \\
\hline $\begin{array}{l}\text { Lo Monte, } \\
\text { et al. } 2011\end{array}$ & $\begin{array}{l}\text { RCT } \\
\text { (BPB vs. LA) }\end{array}$ & 40 & $\begin{array}{l}B P B, 66.15 \\
\pm 7.55 ; \text { LA } \\
66 \pm 7.49\end{array}$ & $\begin{array}{l}\text { Male (23); } \\
\text { Female (17) }\end{array}$ & $\begin{array}{l}\text { Diabetes (15); High blood } \\
\text { pressure (13); Systemic lupus } \\
\text { erythematosus (5); } \\
\text { Glomerulonephritis (4); } \\
\text { Autoimmune vasculitis (3); }\end{array}$ & 100 days & $\begin{array}{l}\text { PI ratio; Venous / arterial } \\
\text { diameter; Vein diameter }\end{array}$ \\
\hline $\begin{array}{l}\text { Sahin, et al. } \\
2011\end{array}$ & $\begin{array}{l}\text { RCT } \\
\text { (BPB vs. LA) }\end{array}$ & 60 & $\begin{array}{l}B P B, 43.4 \\
\pm 10.7 ; \mathrm{LA} \\
46.8 \pm 12.5\end{array}$ & $\begin{array}{l}\text { Male (34); } \\
\text { Female (26) }\end{array}$ & $\begin{array}{l}\text { Diabetes (24); Hypertension } \\
\text { (27); Coronary artery } \\
\text { Disease (21) }\end{array}$ & $\begin{array}{l}3 \text { h; } 7 \text { days; } \\
8 \text { weeks }\end{array}$ & $\begin{array}{l}\text { Radial artery flow; Fistula flow; } \\
\text { Thrill presence }\end{array}$ \\
\hline $\begin{array}{l}\text { Shoshiashvili, } \\
\text { et al. } 2014\end{array}$ & $\begin{array}{l}\text { RCT } \\
\text { (BPB vs. LA) }\end{array}$ & 103 & $\begin{array}{l}B P B, 60.1 \\
\pm 14 ; \angle A \\
59.7 \pm 13\end{array}$ & $\begin{array}{l}\text { Male (68); } \\
\text { Female (35) }\end{array}$ & $\begin{array}{l}\text { Arterial hypertension (87); } \\
\text { Diabetes (18); Ischemic heart } \\
\text { disease (9); Gastric ulcer (1); } \\
\text { Hepatitis B (2); Hepatitis C (7); } \\
\text { Osteoblastoma (1) }\end{array}$ & 100 days & $\begin{array}{l}\text { Intra-operative pain; Need for } \\
\text { intraoperative pain killers; Need } \\
\text { for postoperative pain killers; } \\
\text { Duration of anesthesia (h); } \\
\text { Attitude to the type of anesthesia; } \\
\text { Pain intensity, night sleep; Limb } \\
\text { immobility; Operation duration } \\
\text { (min) }\end{array}$ \\
\hline $\begin{array}{l}\text { Meena, et al. } \\
2015\end{array}$ & $\begin{array}{l}\text { RCT } \\
\text { (BPB vs. LA) }\end{array}$ & 60 & $\begin{array}{l}B P B, 41.33 \\
\pm 12.906 ; \mathrm{LA} \\
47.7 \pm 12.272\end{array}$ & $\begin{array}{l}\text { Male (46); } \\
\text { Female (14) }\end{array}$ & $\begin{array}{l}\text { Diabetes (8); Hypertension (21); } \\
\text { Hypertension (14); IgA (15) }\end{array}$ & $\begin{array}{l}30 \text { min } 48 \\
\text { h; } 2 \text { weeks; } \\
6 \text { weeks }\end{array}$ & $\begin{array}{l}\text { Vessel diameter; Peak systolic } \\
\text { velocity; Mean diastolic velocity; } \\
\text { Blood flow }\end{array}$ \\
\hline $\begin{array}{l}\text { Aitken, et al. } \\
2016\end{array}$ & $\begin{array}{l}\text { RCT } \\
\text { (BPB vs. LA) }\end{array}$ & 126 & $60.8 \pm 14.8$ & $\begin{array}{l}\text { Male (79); } \\
\text { Female (47) }\end{array}$ & $\begin{array}{l}\text { Diabetes (34); Ischemic heart } \\
\text { disease (48); Cerebrovascular } \\
\text { accident (9); Hypertension (93) } \\
\text { Obesity (41) }\end{array}$ & 3 months & $\begin{array}{l}\text { Brachial artery blood flow; } \\
\text { Radiocephalic fistulae; Cephalic } \\
\text { vein (wrist) diameter (mm); } \\
\text { Brachiocephalic fistulae; Brachial } \\
\text { artery diameter (mm); Cephalic } \\
\text { vein (elbow) diameter (mm) }\end{array}$ \\
\hline $\begin{array}{l}\text { Nofal, et al. } \\
2017\end{array}$ & $\begin{array}{l}\text { RCT } \\
\text { (BPB vs. LA) }\end{array}$ & 140 & $\begin{array}{l}\text { BPB, } 39.52 \\
\pm 5.46 ; \text { LA, } \\
42.42 \pm 5.41\end{array}$ & $\begin{array}{l}\text { Male (79); } \\
\text { Female (61) }\end{array}$ & - & $\begin{array}{l}4 \text { h; } 1 \\
\text { week; } 3 \\
\text { months }\end{array}$ & $\begin{array}{l}\text { Radial artery internal diameter; } \\
\text { Cephalic vein internal diameter }\end{array}$ \\
\hline
\end{tabular}

BPB brachial plexus block, IgA immunoglobulin A, GA general anesthesia, LA local anesthesia, MI myocardial infarction, $P /$ pulsatility Index Ratio, $R C T$ randomized controlled trial, $M \pm S D$ mean \pm standard deviatio

study by Sahin et al, [3] improved blood flow in the radial artery was significantly greater post- versus preanesthesia. Moreover, post-anesthesia and immediately pre-surgery, radial artery blood flow was $56 \pm 8.6 \mathrm{~mL} /$ min in the BPB group versus $40.7 \pm 6.1 \mathrm{~mL} / \mathrm{min}$ in the LA group $(P<0.001)$. Finally, Ebert et al [12] reported that both mean arterial and venous blood flow were increased (1.9 and 8.6 times, respectively) after BPB. Thus, we conclude that BPB anesthesia techniques in AVF construction can contribute to vessel dilation and reduced vasospasm via sympathectomy-like effects, increasing fistula blood flow, reducing fistula maturation time, and improving the success rates of vascular access procedures.

Arteriovenous fistulae operations can be performed under GA, LA, or RA. General anesthesia is associated with increased morbidity, [13] such as through cardiorespiratory complications in patients with endstage renal disease, whilst LA is associated with complications such as vasospasm and pain and discomfort during surgery $[10,12,14]$. By comparison, RA (e.g. $\mathrm{BPB})$, which is a targeted injection of LA to specifically block the motor and sensory nerves that supply the operative site, is less complicated than GA and safer than LA [15]. Moreover, BPB can be performed under ultrasound guidance, allowing for more accurate placement of the injection needle as well as more rapid onset and longer duration of the block, reduced vascular and neurological complications, and minimization of the volume of LA required [16, 17].

Pain control is also an important indicator of surgical success. Adequate pain control is extremely important in patients with end-stage renal disease with severe comorbidities [15]. The prospective, randomized, clinical 

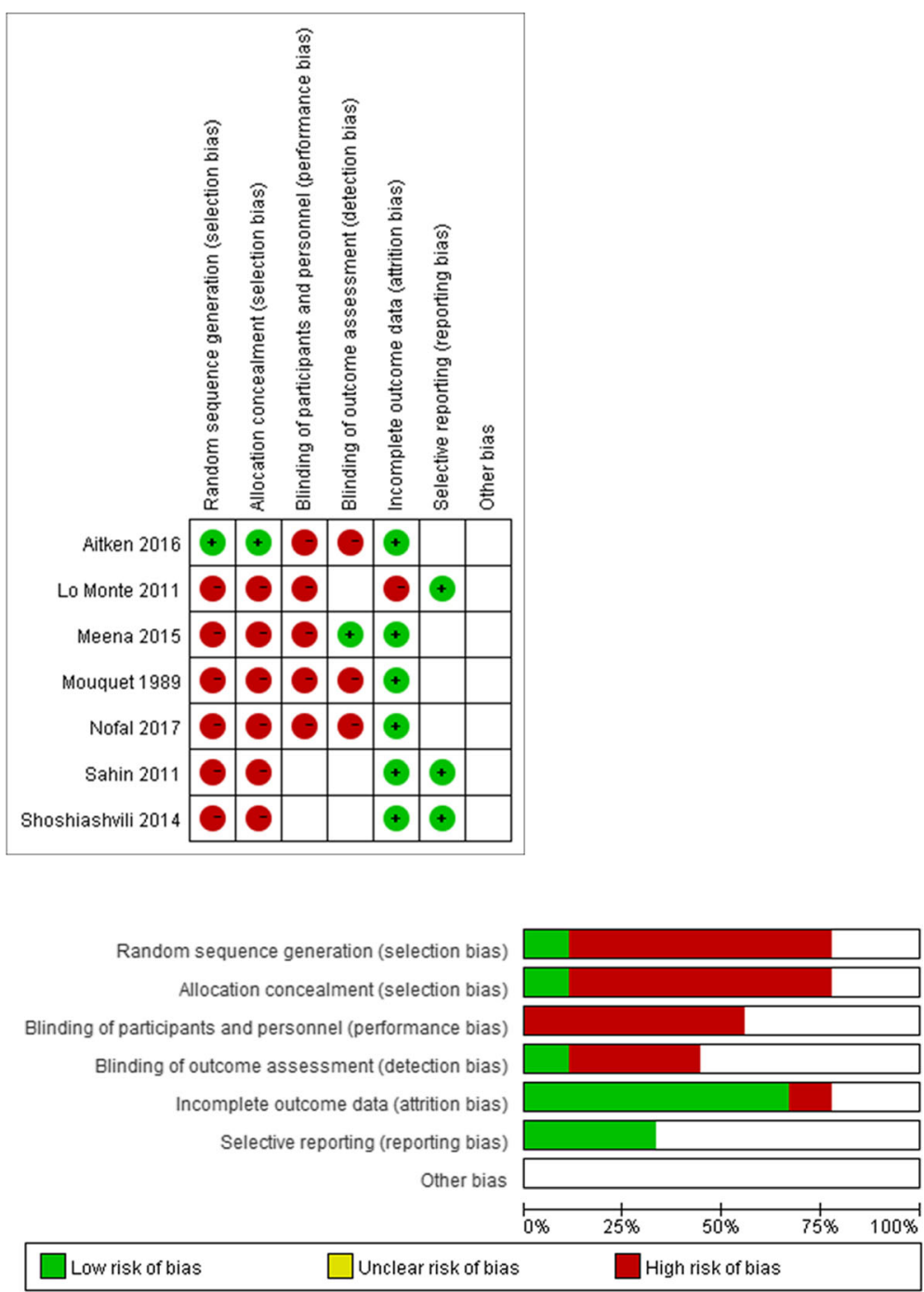

Fig. 2 Risk of bias assessment

study from Shoshiashvili et al [4] showed significantly different results between BPB and LA groups in terms of pain intensity. The need for intra- as well as postoperative pain killers was significantly less in the BPB versus LA group $(P=0.0363$ and $P=0.0318$, respectively).
Moreover, time to postoperative pain initiation was significantly higher in the RA versus LA group. Thus, we conclude that RA provides better pain control intra- as well as post-operatively in dialysis AVF operations, enabling patients to feel more comfortable [5].

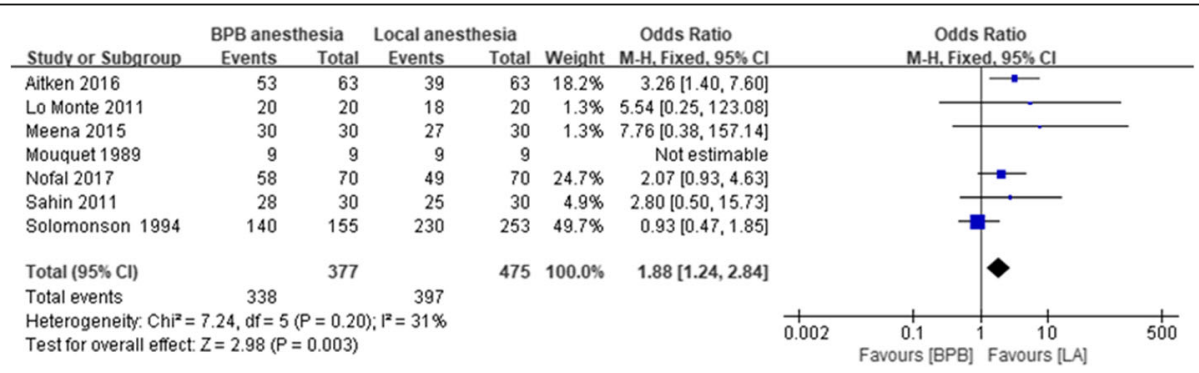

Fig. 3 Patency of brachial plexus block (regional anesthesia) versus local anesthesia 
Table 3 Main clinical results

\begin{tabular}{|c|c|c|c|c|}
\hline Outcome variable & Number of convective therapy study arms & Number of patients & Absolute mean net change $[95 \% \mathrm{Cl}]$ & $1^{2}$ \\
\hline Duration of surgery & 2 & 229 & $-29.63[-32.78,-26.48]$ & $100 \%$ \\
\hline Brachial artery diameter & 3 & 284 & $0.83[0.75,0.92]$ & $97 \%$ \\
\hline Brachial artery blood flow rate & 2 & 144 & $47.15[35.18,59.12]$ & $83 \%$ \\
\hline Complication of infection & 3 & 594 & $0.68[0.23,2.02]$ & $0 \%$ \\
\hline Thrombosis & 3 & 163 & $0.21[0.03,1.27]$ & $0 \%$ \\
\hline Hematoma & 1 & 60 & $0.19[0.01,4.06]$ & - \\
\hline Intraoperative analgesia & 1 & 103 & $0.65[0.30,1.42]$ & - \\
\hline
\end{tabular}

Cl confidence interval, $P^{2}$ inconsistency test

The results of our study are consistent with those of previous meta-analyses. In a systematic review of 6 randomized trials (462 patients) and 1 retrospective study (408 patients), Ismail et al [18] reported that RA improves the primary patency rate of AVF compared to LA. In conclusion, our meta-analysis suggests that RA is preferable to LA in patients with end-stage renal disease in guaranteeing AVF patency and increasing brachial artery diameter.

\section{Limitations}

Our study has several limitations. First, BPB can be performed with interscalene, supraclavicular, infraclavicular and axillar approaches. We included studies using different approaches for $\mathrm{BPB}$, and did not consider the effects of these approaches in our comparison of LA versus RA. Future studies are thus required to explore the effect of different anesthetic approaches on the outcomes of BPB. Second, three of the studies included in this study were single-center trials with an inherent risk of bias. Moreover, there are relatively few primary studies available in the literature. Both factors restrict the generalizability of our findings. Third, only short-term data are reported in the literature; thus, future studies are required to explore longer-term outcomes. Finally, only one study explored patients' attitudes towards anesthesia and, thus, future trials are recommended to explore the differences between LA and RA in terms of patient-oriented outcomes.

\section{Conclusions}

In summary, our meta-analysis suggests that RA is advantageous over LA, providing sufficient branchial artery blood flow to guarantee AVF patency whilst increasing brachial artery diameter to avoid thrombosis and several other related complications. Nevertheless, large, head-tohead RCTs with longer follow-up periods are required to support the use of BPB and illustrate the safety differences between RA and LA.

\section{Abbreviations}

AVF: Arteriovenous fistulae; RA: Regional anesthesia; LA: Local anesthesia; GA: General anesthesia; BPB: Brachial plexus block; RCTs: Randomized controlled trials

\section{Acknowledgements}

Not applicable.

Authors' contributions

$\mathrm{HCH}$ and $\mathrm{CG}$ was involved in the study design, participated in drafting the manuscript and also helped to analyse the study data. CYW, QLY, JLX were participated in study design and drafting the manuscript. All authors have read and approved the manuscript.

Funding

Not applicable.

\section{Availability of data and materials}

The datasets used in the analysis was collected by online search, and the datasets analyzed in the current study are available from the corresponding author on reasonable request.

Ethics approval and consent to participate

Not applicable.

\section{Consent for publication}

Not applicable.

\section{Competing interests}

The authors declare that they have no competing interest.

\section{Author details}

'Department of Nephrology, The Hangzhou Fuyang Hospital of Traditional Chinese Medicine, Zhejiang, Hangzhou, China. ${ }^{2}$ The First Clinical Medical of Zhejiang Chinese Medicine University, Zhejiang, Hangzhou, China.

${ }^{3}$ Department of Internal Medicine, The Affiliated Hospital of Hangzhou Normal University, 126 Wenzhou Road, Zhejiang, Hangzhou, China.

Received: 4 February 2020 Accepted: 24 August 2020

Published online: 31 August 2020

References

1. Riella MC, Roy-Chaudhury P. Vascular access in haemodialysis: strengthening the Achilles' heel. Nat Rev Nephro. 2013;9:348-57.

2. Lo Monte Al, et al. Comparison between local and regional anesthesia in arteriovenous fistula creation. J Vasc Access. 2011;12:331-5. https://doi.org/ 10.5301/JVA.2011.8560.

3. Sahin $L$, et al. Ultrasound-guided infraclavicular brachial plexus block enhances postoperative blood flow in arteriovenous fistulas. J Vasc Surg. 2011;54(3):749-53.

4. Shoshiashvili V, et al. Evaluation of efficacy of regional and local anesthesia techniques in arteriovenous fistula criation for dialysis. Georg Med News. 2014;(236):7-12. 
5. Meena S, et al. Ultrasound-guided supraclavicular brachial plexus anaesthesia improves arteriovenous fistula flow characteristics in end-stage renal disease patients. South Afr J Anaesth Anal. 2015;21(5):12-5.

6. Aitken $\mathrm{E}$, et al. Effect of regional versus local anaesthesia on outcome after arteriovenous fistula creation: a randomised controlled trial. Lancet. 2016; 388(10049):1067-74.

7. Nofal WH, et al. Ultrasound-guided axillary brachial plexus block versus local infiltration anesthesia for arteriovenous fistula creation at the forearm for hemodialysis in patients with chronic renal failure. Saudi J Anaesth. 2017; 11(1):77-82.

8. Mouquet $\mathrm{C}$, et al. Anesthesia for creation of a forearm fistula in patients with endstage renal failure. Anesthesiology. 1989;70(6):909-14.

9. Solomonson MD, Johnson ME, Ilstrup D. Risk factors in patients having surgery to create an arteriovenous fistula. Anesth Analg. 1994;79(4):694-700.

10. Malinzak EB, Gan TJ. Regional anesthesia for vascular access surgery. Anesth Analg. 2009;109:976-80.

11. Malovrh M. The role of sonography in the planning of arteriovenous fistulas for hemodialysis. Semin Dial. 2003;16:299-303.

12. Ebert B, Braunschweig R, Reill P. Quantification of variations in arm perfusion after plexus anesthesia with color Doppler sonography. Anaesthesist. 1995;44:859-62.

13. Brimble KS, Rabbat CG, Schiff D, Ingram AJ. The clinical utility of Doppler ultrasound prior to arteriovenous fistula creation. Semin Dial. 2001;14:314-7.

14. Abrahams MS, Aziz MF, Fu RF, Horn JL. Ultrasound guidance compared with electrical neurostimulation for peripheral nerve block: a systematic review and meta analysis of randomized controlled trials. $\mathrm{Br}$ 」 Anaesth. 2009;102:408-17.

15. Rang $\mathrm{S}$, et al. Anaesthesia for chronic renal disease and renal transplantation. EAU-EBU Update Ser. 2006;4:246-56.

16. Capdevila X, Biboulet P, Morau D, et al. How and why to use ultrasound for regional blockade. Acta Anaesthesiol Belg. 2008;59:147-54.

17. Marhofer P, Schrögendorfer K, Koinig H, Kapral S, Weinstabl C, Mayer N. Ultrasound guidance improves sensory block and onset time of three-inone blocks. Anesth Analg. 1997;85:854-7.

18. Ismail A. Abdelrahman Ibrahim Abushouk: regional versus local anesthesia for arteriovenous fistula creation in end-stage renal disease: a systematic review and meta-analysis. J Vasc Access. 2017;18(3):177-84.

\section{Publisher's Note}

Springer Nature remains neutral with regard to jurisdictional claims in published maps and institutional affiliations.

Ready to submit your research? Choose BMC and benefit from:

- fast, convenient online submission

- thorough peer review by experienced researchers in your field

- rapid publication on acceptance

- support for research data, including large and complex data types

- gold Open Access which fosters wider collaboration and increased citations

- maximum visibility for your research: over $100 \mathrm{M}$ website views per year

At $\mathrm{BMC}$, research is always in progress.

Learn more biomedcentral.com/submissions 